\title{
The role of the cognitive model profile in knowledge representation and meaning construction: the case of the lexical item Europe
}

\author{
Przemysław Wilk ${ }^{1}$ \\ Opole University
}

\begin{abstract}
The paper addresses the role of the cognitive model profile, one of the fundamental constructs in LCCM Theory (a.k.a. access semantics), in meaning construction and knowledge representation with respect to the concept of Europe. The study is based on a corpus of news articles retrieved from the Guardian from May 2004 through December 2009 (approximately 930,000 words) and focuses on the lexical item Europe (over 4000 corpus occurrences). The study takes its theoretical underpinnings from LCCM Theory, a theory of lexical representation and semantic composition, which delineates the roles the linguistic and the conceptual systems play in meaning construction (e.g., Evans 2009, 2013).

The paper documents the immense semantic potential of the lexical item Europe as manifest in the Guardian's discourse under analysis. In terms of knowledge representation, to account for the coherent body of multimodal knowledge which the lexical item Europe affords access to, its cognitive model profiles relevant to its two lexical concepts are constructed. As far as the role of the cognitive model profile in meaning construction is concerned, the study demonstrates how the context, specifically the co-text, determines the activation of a respective portion of the cognitive model profile of the lexical item Europe.
\end{abstract}

Keywords: LCCM Theory, meaning construction, knowledge representation, cognitive model profile, Europe

Corresponding author - Department of the English Language, Institute of English, Opole University, 45-040 Opole, pl. Kopernika 11.

Email: przemekwilk82@gmail.com 


\section{Introduction}

Cognitive semantics, as part of a wider research enterprise termed cognitive linguistics, is primarily concerned with a complex relationship between human experience, the conceptual system and the semantic structure of language (cf. Evans, Bergen \& Zinken, 2007). One of the recent theories that has been developed within the area of study known as cognitive lexical semantics is the Theory of Lexical Concepts and Cognitive Models (LCCM Theory for short) (e.g., Evans 2006, 2009). The theory is basically in keeping with the main tenets of Construction Grammar (cf. Goldberg 1995, 2006) and Langacker's Cognitive Grammar (cf. Langacker 1987, 1991, 2008), yet it proposes quite an innovative approach to the relationship and interaction between the linguistic and the non-linguistic (or conceptual) systems. The theory has come under some criticism, notably by Taylor (2010), in terms of both the paucity of data on which it is built as well as its architecture. While it is difficult not to agree with Taylor's (2010) critical remark concerning the former, in terms of the latter, the architecture and the toolkit of LCCM Theory are well theorized and hence seem to be applicable to semantic analyses, which I will try to prove in the present paper. Admittedly, LCCM Theory is not the only cognitive lexical semantic theory capable of accounting for the language phenomena addressed here, as it is, at least to some extent, consonant with Fillmore's (1982) frame semantics, Lakoff's (1987) Idealized Cognitive Models theory or Langacker's (1987, 1991, 2008) domain approach to conceptual structure.

In the present paper I am concerned with the semantic potential of the lexical item Europe. Specifically, in keeping with one of the main tenets of the cognitive linguistics paradigm, namely, the usage-based approach to the study of language, I attempt to identify, describe and classify the various senses, that is, utterance-level units of meaning, of the lexical item Europe as manifest in the Guardian's press discourse under analysis. Applying the theoretical assumptions and constructs of LCCM Theory, I construct cognitive model profiles relevant to two different lexical concepts of the lexical item Europe. A cognitive model profile can be chiefly understood as a systematized representation of the conceptual content of a particular lexical item. In other words, it is a way to account for knowledge representation in the conceptual system. In terms of meaning construction, I demonstrate the role of the co-text in the differential activation of cognitive models in a given lexical concept's cognitive model profile to establish an utterance-specific reading, or conception in Evans's parlance.

\section{LCCM Theory: An overview}

LCCM Theory (a.k.a. access semantics, cf. Evans, 2013) is a cognitive lexical semantic 
theory of lexical representation and semantic composition developed by Evans (2006, 2009, 2013). Importantly, LCCM Theory subscribes to a usage-based model of language in that it assumes that meaning (or conception in Evans' parlance) arises in situated language use, and hence is not a function of language per se (cf. Evans, 2009). An overview of the architecture of LCCM Theory is diagrammatically represented in Figure 1.

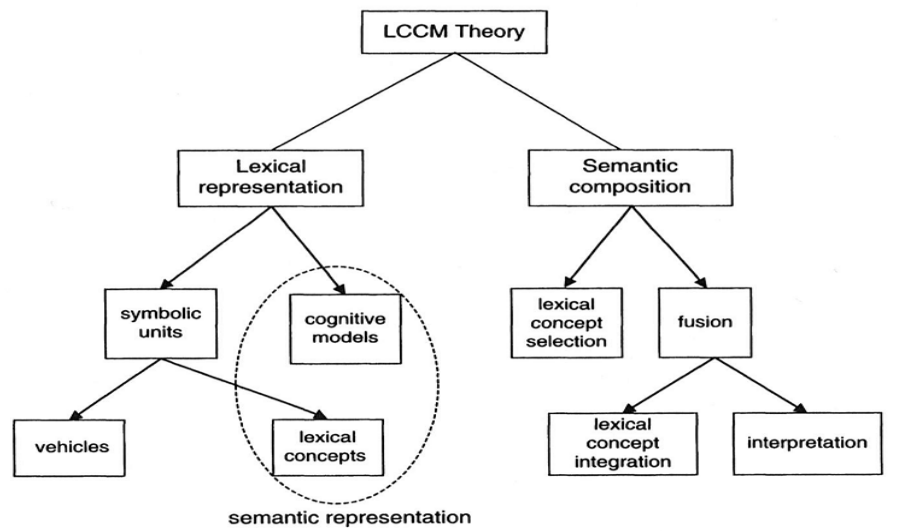

Figure 1. The architecture of LCCM Theory (Evans 2009, 75).

In what follows, first, I delve into some detail of the left-hand side of the diagram, namely, lexical representation as theorized within the framework of access semantics. The discussion aims at specifying the nature of the interaction between the linguistic and the conceptual systems as operationalized in LCCM Theory, which lays foundations for the process of meaning construction. Second, I very briefly discuss the semantic composition dimension of the theory, the right hand side of the diagram, in order to shed some light on the LCCM Theory-specific mechanism of meaning construction as guided by the linguistic system to obtain the final utterance-specific interpretation grounded in the conceptual system. The discussion is meant to be very general and concise at this point but its detailed application in respect of specific language data can be found in Section 4.

As can be inferred from the diagram in Figure 1, lexical representation, which, as Evans $(2009,350)$ puts it, is "the primary substrate in linguistically mediated meaning construction," is made up of symbolic units and cognitive models. The former constitute fundamental units in the linguistic system while the latter underlie the conceptual system. A symbolic unit is precisely what Langacker $(1987,1991,2008)$ calls a symbolic assembly, that is, a pairing of form (a phonological pole) and meaning (a semantic pole), except that the semantic pole is operationalized in LCCM Theory in terms of the lexical concept, a fundamental construct in Evans' theory.

The uniqueness of access semantics lies primarily in the nature of semantic 
representation (represented in Figure 1 as a dotted ellipse), that is, the interaction between lexical concepts and cognitive models. Evans (2009) argues for a principled distinction between semantic structure and conceptual structure and hence the respective roles of the linguistic and the conceptual systems in linguistically mediated meaning construction. It is here that access semantics brings something new to the table as it departs, albeit not entirely, from a fully encyclopedic view of lexical semantics, where the borderline between the linguistic and the conceptual systems is not clearly demarcated. As Evans (2007) claims, the nature of the interaction between lexical concepts and cognitive models is also what distinguishes the notion of cognitive model from frames (cf. Fillmore, 1982) or domains (cf. Langacker, 2008).

Lexical concepts have a bipartite structure and are of two types, namely, closed-class and open-class lexical concepts, a distinction that echoes Talmy's (2000) observation that concepts belong to the grammatical and lexical subsystems of language. Both types of lexical concepts encode some highly schematic linguistic content, such as the range of their collocational and collostructional tendencies, referred to in LCCM Theory as formal and semantic selectional tendencies (cf. Evans, 2009, 2013). Openclass lexical concepts serve, additionally, as access sites to the conceptual content, that is, to a wide range of cognitive models, which make up a lexical item's semantic potential. Open-class lexical concepts prompt for the activation of our rich conceptual content, which is re-activated as simulation (cf. Bergen, 2012).

The cognitive model is a large-scale structured body of multimodal (hence nonlinguistic), knowledge which derives from human sensory-motor, proprioceptive and subjective experiences (cf. Evans, 2013). Importantly, cognitive models are dynamic knowledge structures as they are capable of being constantly updated in terms of our ongoing interactions with the outside world, which give rise to newer and newer experiences, which, in turn, have a direct bearing on our knowledge of the world.

A fundamental construct in LCCM Theory is the cognitive model profile, that is, the range of cognitive models that a lexical concept affords both direct and indirect access to. Hence, a cognitive model profile constitutes a semantic potential of a given lexical concept. There are two basic types of cognitive models recognized within the LCCM Theory framework, namely, primary cognitive models, the ones to which a lexical concept facilitates direct access, and secondary cognitive models, which are linked to the primary ones and hence are accessed indirectly. The classification of cognitive models into the primary and the secondary ones lies at the heart of the operationalization of literal and figurative meaning within access semantics. Literal conceptions are associated with the primary cognitive model profile whereas figurative conceptions are a function of the secondary cognitive model profile. Hence, it also follows that primary cognitive models are more central 
knowledge types compared to the secondary cognitive models, which are more peripheral.

In keeping with the basic assumptions of the cognitive linguistic paradigm, the human conceptual system is not chaotic in nature but is highly structured. Evans' notions of the cognitive model and the cognitive model profile, as established in LCCM Theory, are the theoretical constructs which are claimed to be able to account for the complex and multilayered structure of the human conceptual system. Specifically, primary and secondary cognitive models, which are chained to one another in a principled way, constitute an interrelated network of cognitive models, which, in turn, accounts for the organization of knowledge in the conceptual system. Hence, the cognitive model profile stands for knowledge representation of a given concept. Evans $(2013$, p. 36) provides a set of characteristics a likely candidate for a primary cognitive model should meet, namely, the knowledge constituting such a cognitive model should be conventional, generic, intrinsic and/or characteristic (for a discussion and illustration of the four knowledge types see also Evans \& Green, 2006) in respect of a lexical concept that affords access to a given cognitive model. Nevertheless, any judgments concerning the type of knowledge a given cognitive model represents are necessarily based on the researchers' intuition and their current state of knowledge. Hence, any cognitive model profile, which should account for (a part of) the architecture of the conceptual system, is established probabilistically, at least to some extent. It follows that, given the current state of knowledge on the nature of the human conceptual system, any attempt to account for a representation of a given portion of knowledge is bound to be putative, to a greater or lesser extent.

As far as the process of meaning construction is concerned, there are three basic processes which act jointly to produce an utterance-specific conception, namely, lexical concept selection, integration and interpretation. Lexical concept integration and interpretation are jointly referred to as fusion (see Figure 1). Lexical concept selection ensures that in the linguistic context, co-text specifically, the most appropriate lexical concept associated with a particular phonological vehicle is picked out. As soon as a particular lexical concept has been selected, it undergoes the process of integration, whereupon this particular lexical concept is integrated with other lexical concepts that make up the utterance to form a lexical conceptual unit. In this way the lexical concept obtains its reading thanks to the process of interpretation, which might be understood as establishing a particular access route in the cognitive model profile of the lexical concept to activate a relevant cognitive model in the context of the utterance. The final outcome of the three processes involved in semantic composition is the lexical concept's utterance-specific meaning, technically referred to in access semantics as conception. 


\section{Data collection and processing}

The source of my language data is a manually compiled 930,000-word corpus of news articles (here also referred to as news items), retrieved from the Guardian, a liberal British daily quality newspaper, from May 2004 through December 2009. The articles are available in the Guardian's online archive at www.guardian.co.uk. The key word for the selection of the language data was the occurrence of the lexical item EU in the headline of the article. The choice of this particular lexical item as a key word allowed me to include in the search results such lexical items as the nouns $E U$, Europe and European and the adjective European. Moreover, I have included in my search results only the articles which occurred in one of the three sections of the Guardian, namely, (1) UK news, (2) World news and (3) Politics. It follows that my corpus of news items is clearly thematically focused, that is, it reflects a specific area of human cognition, namely, Europe in its political and economic contexts.

Since my aim in the present paper is to investigate the semantic potential of the lexical item Europe, the specific language data subject to analysis in Section 4 comprise a total corpus occurrence of the lexical item Europe which amounts to 4234 instances. To facilitate the process of data analysis, I used the computer software WordSmith Tools 4.0, which offers a number of tools for text analysis (cf. Scott, 1996). What I found particularly useful was a concordance facility, which allowed me to see all the instances of the lexical item Europe in their contexts of occurrence. Moreover, utilizing a patterns option, I was able to establish some patterns of repeated phraseology in the concordance. The two text analysis facilities offered by WordSmith Tools 4.0 made it possible for me to enhance the analysis of the 4,234 instances of the lexical item Europe in the real context of language use and to establish a variety of its conceptions as manifest in the language corpus. Importantly, having identified a given conception, I manually tagged my corpus to be able to refine and tune the results of the concordance analysis. The tagging consisted in ascribing a particular label contained in square brackets to a given occurrence of the lexical item Europe in the corpus. This procedure allowed me to produce concordance lists relevant to particular conceptions of the lexical item Europe. Hence, I was able to observe the linguistic patterns of the use of the lexical item Europe relevant to its particular meaning.

\section{Analysis and discussion}

At the beginning of the analytical section, it is crucial to establish some typographic conventions to be used throughout the paper. First, following Evans' (2009) convention, I use italicized regular typeface to indicate lexical items and to refer to quoted language in the main text of the article; I use capitals in square brackets to 
refer to lexical concepts. Second, when quoting relevant material, I use boldface to indicate the specific language under analysis. A symbol in the parentheses following each example is the symbol of the article as listed in the Appendix, which features only the news articles I used in order to illustrate particular conceptions of the lexical item Europe with relevant linguistic context. It is also critical to explain one terminological issue that may be found striking, given the cognitive semantics inclination of the paper. In what follows I use the terms meaning, reading and conception interchangeably although I am very much aware of some possible terminological quibbles connected with such a simplification.

The analysis and discussion contained in this section follow a specific structure of presentation. At the beginning, I introduce all the eleven conceptions of the lexical item Europe I was able to identify in my language data. The order of their listing is not accidental: the conceptions are divided chiefly into two groups which reflect the two basic kinds of knowledge associated with the lexical item Europe under analysis, namely, the conceptions related to the 'European Union' sense of the lexical item and the conceptions reflecting the 'continent' sense (a detailed discussion and further implications stemming from this fundamental distinction can be found in the following paragraphs of this section). I then discuss the conceptual content of the eleven conceptions, illustrating each one with a context embedded example to give the reader an idea of what kind of knowledge constitutes each particular conception. Finally, I construct a plausible, though necessarily tentative (see my remarks in Section 2), cognitive model profile which captures the complex knowledge structure constituting the semantic potential of the lexical item Europe as manifest in the corpus.

In the language data under analysis, I was able to identify eleven different senses of the lexical item Europe. It is worth noting that the glosses I use below to identify a particular conception correspond to the labels I used to tag my corpus and hence they will recur in the examples provided. The eleven conceptions of the lexical item Europe are as follows:

(1) 'EU politico-economic entity' ('EU' for short) (2,869 instances),

(2) 'EU authorities' (517 instances),

(3) 'EU member states' (436 instances),

(4) 'EU member states representatives' (36 instances),

(5) 'EU citizens' (33 instances),

(6) 'EU member states citizens' (1 instance),

(7) 'EU president' (1 instance)

(8) 'EU voting' (1 instance)

(9) 'EU constitution' ( 1 instance)

(10) 'geopolitical region' (264 instances),

(11) 'geographical region' (27 instances). 
Importantly, when analysing the corpus, I came across 48 occurrences of the lexical item Europe whose semantics was not transparent and hence I was not able to make an unequivocal and informed decision as to their particular conception. As a result I devised the [ambiguous] label to tag these corpus examples of the lexical item Europe. These were cases of reference to the position of the journalist who wrote the article (e.g. Goop Meinen, Europe[ambiguous] editor at the NRC Handelsblad newspaper, in Rotterdam; Ian Traynor, Europe[ambiguous] editor) or names of some companies and organization (e.g., Organisation for the Security and Cooperation in Europe[ambiguous] (OSCE); the financial news channel CNBC Europe[ambiguous]).

The most frequent conception of the lexical item Europe identified in the language data subject to analysis is the 'EU' conception. The idea behind this gloss is that the meaning of the EU evoked here pertains to the European Union as an established institution with its hierarchy, political, economic and social systems, as well as its populace. Hence, it is the most schematic and general (in terms of the level of specificity of the concept EU) conception of the EU. Excerpt (1) provides an example thereof.

$$
\begin{aligned}
& \text { Since the abortive June summit and the launch of the UK presidency, } \\
& \text { Tony Blair has made EU reform his call to arms. But recent studies have } \\
& \text { shown that Europe[EU]'s economic performance is by no means as far } \\
& \text { behind the US as some would have us believe, and that the UK's mar- } \\
& \text { ket-oriented reform model, based as it is on a buoyant property mar- } \\
& \text { ket, is not so sustainable after all. (A1) }
\end{aligned}
$$

In example (1) the 'EU' meaning of the lexical item Europe is arrived upon thanks to the context of the previous sentence, which features the noun phrase EU reform. The noun phrase Europe's economic performance gives rise to the most general meaning of the EU as a politico-economic entity as the phrase refers to the economic situation not only of the individual member states but, more importantly, of the EU as one institutional body.

The second most common meaning of the lexical item Europe as manifest in the corpus is the 'EU authorities' conception. The meaning is constituted by the conventional knowledge that any institution or organization necessarily has people managing it. In the case of the EU, which is multifaceted and has a clear structure and hierarchy, there are many institutional bodies that together comprise the legislative and executive mechanism of the EU. However, the EU_authorities conception, as understood in the present paper, is concerned with the representative and widely recognized authorities of the European Parliament, the European Council and the Council of the EU, which constitute the core of the EU 
legislative and executive system, as well as the European Commission, the agendasetting body, who on a regular basis speak on behalf of the EU as a whole. These four institutions are the four main pillars of the EU as compared with other institutional bodies of lesser importance, such as the Committee of Regions or the European Ombudsman, for example. Excerpt (2) neatly illustrates this point.

Europe[EU_authorities] badly wanted John Kerry to win the US presidential election, hoping for a fresh start that would turn the bitter disagreements of the Iraq war into a thing of the past, even if it was always widely acknowledged that achieving it would be far from easy. (A2)

In excerpt (2) the lexical item Europe prompts for the EU_authorities conception as the talks concerning joint military activity in Iraq undertaken by the USA and the EU definitely are executed by authorities at the institutional level and hence have nothing to do with ordinary citizens. In terms of the linguistic co-text, it is the past form of the verb want that activates the EU authorities cognitive model associated with the lexical concept [EU] as it coerces the reading of the noun phrase in which an animate being, human actors in this case, is at the center of conceptualization.

The 'EU member states' conception of the lexical item Europe draws on the conventional knowledge that the EU consists of member states ( 28 members by the year $2016^{2}$ ). What distinguishes this conception from the 'EU politico-economic entity' conception is the fact that while the latter is based on the idea of the EU as one homogeneous whole, that is, the EU as one coherent institutional body, the former relies upon the concept of the EU as being composed of separate and individual member states, which underlies its heterogeneity ${ }^{3}$. The conceptual content of the 'EU member states' conception is illustrated by example (3).

Tony Blair yesterday defended plans to offer a $£ 1$ bn a year cut in Britain's EU rebate, saying compromise was necessary to secure prosperity in eastern Europe[EU_member_states] and an overall budget deal at the EU summit in a fortnight. (A3)

In (3) this heterogeneous nature of the EU is contextually evoked in the following way: first, from the context of the excerpt it seems clear that Britain's EU rebate to be agreed upon during the EU summit may be of any concern only to the members of

2 Although on June 23, 2016 the UK citizens decided to leave the EU in a national referendum, throughout the year 2016 the UK was still formally an EU member.

3 In cognitive linguistics literature, a grammatical number variation in the semantics of a particular lexical item is the function of construing its conceptual content in alternate ways. The construal operative in this case is referred to as plexity (cf. Talmy, 2000). 
the EU and not to any non-EU members; second, the adjective eastern evokes a clear boundary between the east and the west. Since it is logical to claim that the ontological status of such concepts as eastern or western European Union is dubious, to say the least, it needs to be concluded that the conception that is prompted for in this context concerns the EU as a collection of member states. It follows then that what eastern Europe stands for here is the EU member states from eastern parts of the European continent, which is based on the long established divide between the east and the west of Europe established at the political times of the Iron Curtain.

The 'EU member states governments' conception is closely related to the previous sense of the lexical item Europe as it is founded upon one of the basic tenets of the $\mathrm{EU}$, namely, the fact that each EU member is unique and is represented by its own government, whose responsibility is to look after the best interest of its citizens and the nation state within the EU. This translates into the fact that not infrequently some dissonance between the member states with respect to some burning issues of relevance to the whole EU occurs, which is exactly what excerpt (4) illustrates.

$$
\begin{aligned}
& \text { On the continent, the Blair government lost the sympathy of much of } \\
& \text { western Europe[EU_member_states_representatives] over Iraq; now } \\
& \text { it risks losing the sympathy of central and eastern Euro- } \\
& \text { pe[EU_member_states_representatives] over the budget. (A4) }
\end{aligned}
$$

We learn here that Tony Blair has lost a number of allies in western Europe over the Iraq issue and risks losing some in eastern Europe as well. Since the verb phrase to lose sympathy of selects for a plus human compliment, it coerces a plus human conception of the noun phrases western Europe and eastern Europe. Additionally, the fact that the EU is not conceived here as one coherent body capable of any unanimous decision on the issue prompts for the 'EU member states representatives' reading. Obviously, the support for the Iraq intervention is either won or lost at the EU level, yet in order to secure a desired voting result in any of the EU institutional bodies, it is first necessary to convince the EU representatives of particular national governments as to the legitimacy of particular convictions.

Another sense of the lexical item Europe identified in the corpus is the 'EU citizens' conception. It is constituted by the conventional knowledge that in the EU there live over 500 million people who identify themselves, to a greater or lesser extent, with the EU community. Example (5) illustrates how this conception arises in context.

$$
\begin{aligned}
& \text { In sharp contrast to the US, Europe could shape a new, prosperous and } \\
& \text { peaceful accommodation between Islam and the secular west. But this } \\
& \text { is the nub of the problem - vast swaths of Europe[EU_citizens] don't } \\
& \text { buy it. Either they don't believe a peaceful accommodation with Mus- }
\end{aligned}
$$


lims is possible or they fear it requires such a dilution of European identity that they don't want it. (A5)

In (5) we can see that a peaceful accommodation with Muslims does not sit easily with the majority of Europe's inhabitants. Interestingly, although the noun swaths could imply a kind of Europe-as-land interpretation of the lexical item Europe, the 'EU citizens' reading is established here due to the verb phrase don't buy it, which is an informal way of saying that people do not believe or agree with what others are trying to talk them into. Additionally, the auxiliary verb do in the verb phrase is in the plural, which encodes the multiplex construal of the lexical item Europe. Hence, it is reasonable to draw a conclusion that in this example it is the 'EU citizens' conception that is contextually evoked.

The following four senses (see examples 6, 7, 8 and 9) of the lexical item Europe should be considered marginal ones in light of their very low frequency of occurrence, that is, each sense occurs only once in the corpus. They do, nevertheless, constitute part of the semantic potential of the lexical item Europe, illustrating high creativity of press discourse on the one hand and, more importantly, the dynamic and seemingly unconstrained character of human conceptualization on the other (especially the senses represented in examples 7, 8 and 9).

Populists seize the moment as discontent grips central Europe[EU_member_states_citizens] (A6)

A sizeable salary, a generous housing allowance, renovated offices in an art deco pile, cars, chauffeurs, a security retinue and a hand-picked staff await Mr or Ms Europe[EU_president] (A7) The new Europe[EU_constitution] in 333 pages (A8)

Europe[EU_voting] Results, especially in the 10 new member states, show apathy and disenchantment about the union and its parliament (A9)

There is one important fact to be noticed in terms of the four examples presented above, namely, all constitute one of the strategic component parts of the news article which need to be concise and creative enough to compel the readers' attention and to encourage them to pursue reading the whole article. Specifically, examples 6 and 8 are headlines, example 9 is a sub-head, and example 7 constitutes the opening line of the article.

As far as example (6) is concerned, it seems that the 'EU member states citizens' conception of the lexical item Europe is a pretty regular and predictable metonymic extension of the 'EU member states' sense. It is prompted for by the noun discontent, which requires a human actor in the context of the headline. 
The remaining three conceptions are slightly more creative conceptualizations of Europe. A caveat is due at this point. The three senses are utterly hinged on not only the co-text but more importantly the context of the whole news item. Hence, instead of providing a broader context for each of the three examples here, I decided to give the reader only a hint of what the whole article is about and to reproduce more extensive parts of the relevant news articles in the Appendix. Embedded in the context of presidential elections in the European Union, example (7) shows that the lexical item Europe, preceded by the honorifics Mr or Ms, obtains the 'EU president' reading. In example (8), which derives from an article discussing the nuts and bolts of the then EU-constitution-to-be, it is the prepositional phrase in 333 pages that prompts for the 'EU constitution' reading of the lexical item Europe. Finally, in the context of the general European Parliament elections held in 2004, the lexical item Europe as part of the Europe Results compound noun in example (9) obtains the 'EU voting' reading. This is a particularly dynamic conceptualization as it is the function of the cognitive process of conceptual reification, whereupon an event as a temporal relation is construed as a single atemporal conceptual entity (cf. Langacker, 1987, 1991, 2008).

At this juncture we move on to the discussion and presentation of the two senses of the lexical item Europe which are related to the 'continent' sense of the lexical item. The 'geopolitical region' conception is founded upon the common conventional knowledge that Europe is one of the continents populated by different nations who inhabit clearly delimited areas of land, generally referred to as nation states, with their particular political, economic, social, cultural etc. systems and hierarchies. It follows that this conception is not related to the 'European Union' sense but concerns Europe, the continent, as a geopolitical region of the world. Example (10) is an illustration of this fact.

Mr Verheugen acknowledged that Belarus, often described as Europe[geopolitical_region]'s last dictatorship, was especially problematic. Relations between Brussels and Minsk have been frozen for seven years. (10)

In (10) Europe is unequivocally defined as a structure which Belarus is part of. Since Belarus, to this day, does not belong to the European Union, it seems obvious that the 'EU' conception cannot be at play in this example. Hence, the head noun in the noun phrase Europe's last dictatorship invites the reading of Europe as a geopolitical part of the world as it denotes a particular, albeit not approved of by the EU community, political system.

The final conception of the lexical item Europe discussed in this article is the 
'geographical region' sense. It rests upon our knowledge that the landmass of our planet is by means of convention divided into geographical regions with their characteristic lay of the land as well as flora and fauna. What makes it different from the previous reading is the fact that the knowledge related to socio-political facets is not activated.

The experts agreed to step up the surveillance of migratory birds amid fears that they could carry the highly pathogenic H5N1 as they head to the warmer climes of western Europe[geographical_region] from Siberia. (A11)

The context of example (11) concerns migration practices of birds as they move from one continent to another in search for more hospitable weather conditions. While it could possibly be argued that there is, albeit indirect, reference to the human factor in the form of the noun fear, it seems that this facet of meaning, if evoked at all, is backgrounded with respect to the geographical knowledge which is much more salient in the context.

In the reminder of this section, I demonstrate how such a complex knowledge structure characteristic of the lexical item Europe as manifest in the press discourse under analysis can be represented in a coherent manner. I claim that such a diversified and multilayered conceptual content of the lexical item Europe can be elegantly represented as a structured network of cognitive models referred to in access semantics as a cognitive model profile. Moreover, I address the issue of how the linguistic context (co-text specifically) activates different portions of the conceptual content of the lexical item Europe. In other words, I illustrate the role of the interaction between the linguistic and the conceptual systems in (online) meaning construction.

An important observation to be made before presenting the knowledge structure, that is, the semantic potential, of the lexical item Europe is the fact that it is highly polysemous. It is time now to go back the fundamental distinction I made at the beginning of Section 4, namely, all the eleven conceptions of the lexical item Europe have been claimed to be related either to the 'European Union' or to the 'continent' sense of the lexical item. In light of the LCCM Theory, this distinction translates into the fact that the (phonological) vehicle of the symbolic unit Europe is conventionally associated with both the [EU] and [CONTINENT] lexical concepts (see Figure 1), which afford access to our rich multimodal knowledge representation in the conceptual system. Partial cognitive model profiles for the lexical concepts [EU] and [CONTINENT] are diagrammatically represented in Figure 2 and Figure 3 respectively. Importantly, these cognitive model profiles have been established probabilistically, and claim no right to be complete or exhaustive. 


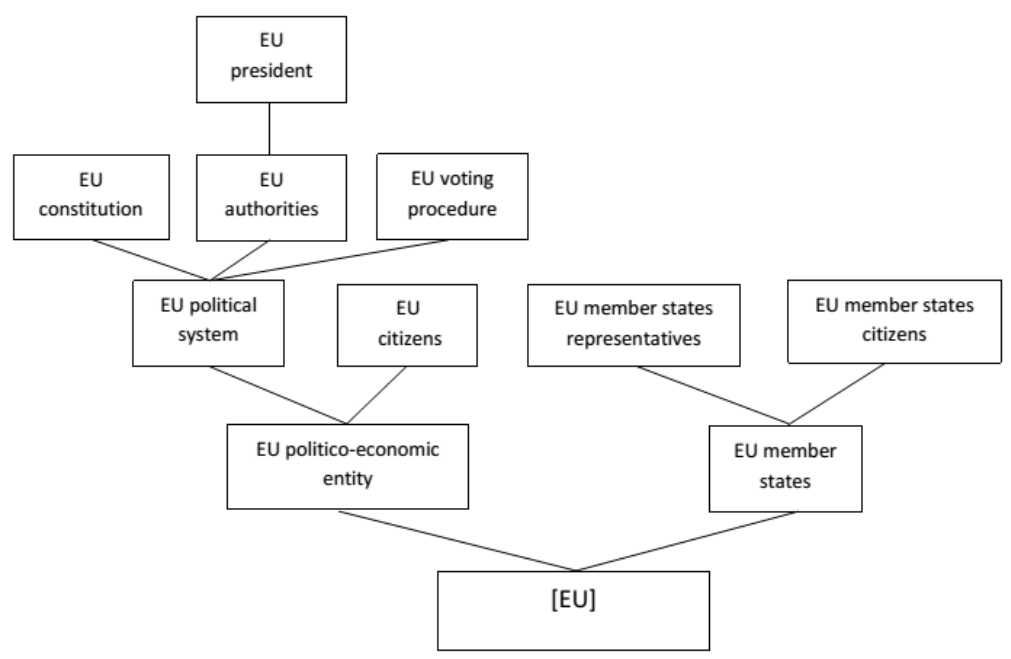

Figure 2. A partial cognitive model profile for [EU].

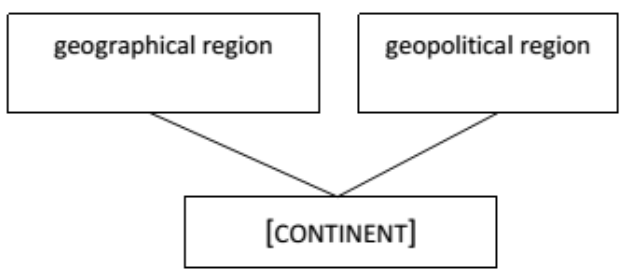

Figure 3. A partial cognitive model profile for [CONTINENT].

Comparing the two cognitive model profiles, it is visible in an instant that the one for [EU] is characteristic of not only a much greater variety of senses but also multiple levels of organization of cognitive models in the conceptual system. To reiterate, as operationalized in the framework of access semantics, any sense that arises as the result of cognitive model activation in the secondary cognitive model profile amounts to figurative interpretation (see Section 2). For example, while 'EU politicoeconomic entity' is a literal conception as it is obtained in the primary cognitive model profile, the 'EU citizens' sense is already the result of figurative interpretation as it is activated in the secondary cognitive model profile. It is now clearly visible that the majority of the conceptions are figurative language uses. Importantly, it should not be overlooked that all the figurative senses of the lexical item Europe indentified 
in the process of my corpus analysis are metonymic extensions: not a single conception is hinged on metaphor, for example. This situation seems to corroborate the claim that metonymy seems to be "one of the most fundamental processes of meaning extension, more basic, perhaps than metaphor" (Taylor, 2002, p. 325). In the context of the present study the fact that metonymy is the fundamental mechanism of sense extension is, perhaps, little surprising, given the fact the in any news article space is at a premium and hence what is highly desired is expressing meaning in as a concise way as possible, which is exactly what metonymy guarantees.

Turning to meaning construction, it is important to remember that in LCCM Theory it is the result of the interaction between the linguistic and the conceptual systems. To reiterate, meaning construction is guided by two fundamental processes, that is, lexical concept selection and fusion, which is further divided into lexical concept integration and interpretation (see Figure 1). To illustrate the exact step-by-step process of arriving upon an utterance-specific conception, I will use the example of the 'EU authorities' senses of the lexical item Europe (see example 2). Although a general suggestion of how this particular sense is arrived upon in the context of example (2) was given earlier, here I provide a more in-depth and principled analysis of how meaning is constructed in light of LCCM Theory-specific toolkit.

As has already been indicated, the lexical item Europe is conventionally associated with the [EU] and [CONTINENT] lexical concepts (see Figures 2 and 3). Example (2) in general concerns the domain of politics and political relations between the EU and the USA and hence in the first step of semantic composition, namely, the process of lexical concept selection, it is the [EU] lexical concept that is selected and further undergoes fusion. Next, during the process of lexical concept integration, the lexical concept [EU] is integrated with the remaining lexical concepts of the utterance in (2). It is important to notice that the utterance is embedded in the active voice construction, which results in that the lexical item Europe fills in the subject slot in the construction. This has some crucial implications for it is primarily the lexical verb want in the predicate that guides the process of interpretation of the lexical concept [EU] selected for in the first step of semantic composition. Specifically, the integration of the lexical concept [EU] with the lexical concept [EXPRESSION OF A DESIRE] for the lexical item want gives rise to a human-being reading ${ }^{4}$. Since the context of (2) concerns shared interests of the EU as a political institutional body, in the process of interpretation the access route is established via the 'EU politicoeconomic entity' primary cognitive model to activate the 'EU authorities' secondary

It should be noticed that the lexical verb hope for in the phrase hoping for a new start guides the interpretation of the lexical concept [EU] in a similar fashion. 
cognitive model, which constitutes the utterance-specific conception of the lexical item Europe. It will be remembered that any conception resulting for the activation of a particular cognitive model in the secondary cognitive model profile amounts to figurative language. In this particular case, we are dealing with the process of metonymic sense extension.

\section{Conclusions}

The article has discussed the issues of meaning construction and knowledge representation as operationalized in the framework of LCCM Theory, emphasizing the fundamental role of the cognitive model profile in both. Notwithstanding some criticism leveled against the design and architecture of LCCM Theory (e.g., Taylor, 2010), this study has proven that the LCCM Theory-specific toolkit is perfectly capable of accounting for the process of meaning construction and knowledge representation with respect to real language data. Specifically, the vast semantic potential of the lexical item Europe as manifest in the Guardian's press discourse has been analyzed. It has been demonstrated that the majority of the 11 senses of the lexical item Europe are figurative readings obtained as a result of the process of metonymic sense extension. To address the issue of knowledge representation, the article has proven that the theoretical construct of the cognitive model profile is an elegant way to account for a complex knowledge structure in the conceptual system that the lexical item Europe affords access to. In particular, acknowledging the fact that the lexical items Europe is characteristic of polysemy in that all its specific senses are associated with either the 'European Union' or the 'continent' interpretation, two partial cognitive model profiles, one for the lexical concept [EU] and the other for the lexical concept [CONTINENT], have been drawn up to represent its immense semantic potential. The cognitive model profile for [EU] constitutes a particularly illustrative example of how conceptually complexity, including figurative metonymic sense extensions, can be represented in a principled and structured fashion. The article has also demonstrated how meaning construction is handled in the framework of access semantics by means of three processes, namely, lexical concept selection, integration and interpretation. It has been shown how a particular conception is arrived upon as a result of the interaction between the linguistic and the conceptual system. Specifically, it has been illustrated how the co-text guides the interpretation of a particular lexical concept by establishing a unique access route via a cognitive model profile to activate its particular portion, that is a specific cognitive model. 


\section{About the author}

Przemysław Wilk is Assistant Professor in the Department of the English Language, Institute of English, Opole University. His research interests range from (Critical) Discourse Studies to Cognitive Linguistics. He is the author of a monograph and several articles on some applications of Cognitive Linguistics in the Critical Discourse Analysis framework. His latest research falls within the field of cognitive lexical semantics.

\section{Article history}

Paper received: 07 February 2017

Paper received in revised form and accepted for publication: 27 April 2017

\section{References}

Bergen, B.K. (2012). Louder than words: The new science of how the mind makes meaning. New York: Basic Books.

Evans, V. (2006). Lexical concepts, cognitive models and meaning construction. Cognitive Linguistics, 17, 491-534.

Evans, V. (2007). A glossary of Cognitive Linguistics. Edinburgh: Edinburgh University Press.

Evans, V. (2009). How words mean: lexical concepts, cognitive models, and meaning construction. Oxford: Oxford University Press.

Evans, V. (2013). Language and time: A Cognitive Linguistics approach. Cambridge: Cambridge University Press.

Evans, V. \& Green, M. (2006). Cognitive Linguistics: An introduction. Edinburgh: Edinburgh University Press.

Evans, V., Bergen, B.K. \& Zinken, J. (2007). The cognitive linguistic enterprise: An overview. In V. Evans, B.K. Bergen \& J. Zinken (Eds.), The cognitive linguistics reader (pp. 2-36). London: Equinox.

Fillmore, Ch. (1982). Frame Semantics. In Linguistic Society of Korea (Ed.), Linguistics in the morning calm (pp. 111-137). Seoul: Hanshin Publishing.

Goldberg, A.E. (1995). Constructions: A Construction Grammar approach to argument structure. Chicago: University of Chicago Press.

Goldberg, A.E. (2006). Constructions at work: The nature of generalization in language. Oxford: 
Oxford University Press.

Lakoff, G. (1987). Women, fire, and dangerous things: What categories reveal about the mind.

Chicago: University of Chicago Press.

Langacker, R.W. (1987). Foundations of Cognitive Grammar: Vol. 1. Theoretical prerequisites. Stanford, CA: Stanford University Press.

Langacker, R.W. (1991). Foundations of Cognitive Grammar: Vol. 2. Descriptive application. Stanford, CA: Stanford University Press.

Langacker, R.W. (2008). Cognitive Grammar: A basic introduction. Oxford: Oxford University Press.

Scott, M. (1996). Wordsmith Tools. Oxford: Oxford University Press.

Talmy, L. (2000). Towards a Cognitive Semantics (Vols. 1 and 2). Cambridge, MA: MIT Press.

Taylor, J.R. (2002). Category extension by metonymy and metaphor. In R. Dirven \& R. Pörings (Eds.), Metaphor and metonymy in comparison and contrast (pp. 323-47). Berlin: Mouton de Gruyter.

Taylor, J.R. (2010). Review of how words mean: Lexical concepts, cognitive models, and meaning construction by V. Evans. Journal of Linguistics, 46, 503-508.

\section{Appendix}

\begin{tabular}{|l|l|l|}
\hline $\begin{array}{l}\text { Article } \\
\text { symbol }\end{array}$ & Author and date & Article headline \\
\hline A1 & John Monks, Sept 7, 2005 & Europe is all we've got \\
\hline A2 & lan Black, Nov 3, 2004 & What a Bush win will mean for Europe \\
\hline A3 & $\begin{array}{l}\text { Patric Wintour and Nicholas } \\
\text { Watt, Dec 3, 2005 }\end{array}$ & $\begin{array}{l}\text { Blair says } \text { 11 bn EU rebate cut is price that } \\
\text { must be paid }\end{array}$ \\
\hline A4 & $\begin{array}{l}\text { Timothy Garton Ash, Dec 8, } \\
2005\end{array}$ & $\begin{array}{l}\text { When we are all equally unhappy, Europe } \\
\text { will finally have a deal }\end{array}$ \\
\hline A5 & $\begin{array}{l}\text { Madeleine Bunting, Sept 26, } \\
2005\end{array}$ & $\begin{array}{l}\text { Regime change, European-style, is a meas- } \\
\text { ure of our civilisation }\end{array}$ \\
\hline A6 & Ian Traynor, Oct 16, 2006 & $\begin{array}{l}\text { Populists seize the moment as discontent } \\
\text { grips central Europe }\end{array}$ \\
\hline A7 & Ian Traynor, Nov 19, 2009 & $\begin{array}{l}\text { EU presidential perks: a villa to live in, an } \\
\text { Art Deco palace for work }\end{array}$ \\
\hline A8 & Ian Black, June 19, 2004 & The new Europe in 333 pages \\
\hline A9 & lan Black, June 14, 2004 & Record low turnout marks EU voting \\
\hline A10 & Ian Black, May 13, 2004 & $\begin{array}{l}\text { EU sets out how new neighbours can be- } \\
\text { come good friends }\end{array}$ \\
\hline A11 & Nicholas Watt, Aug 27, 2005 & EU legal row over bird flu precautions \\
\hline
\end{tabular}

